\title{
Jaundice in non-cirrhotic primary biliary cirrhosis: the premature ductopenic variant
} F P Vleggaar, H R van Buuren, P E Zondervan, F J W ten Kate, W C J Hop, the Dutch
Multicentre PBC study group
See appendix for details of the Dutch Multicentre PBC study group.

Correspondence to: $\mathrm{H} R$ van Buuren, Department of Gastroenterology and Hepatology, University Hospital Rotterdam, PO Box 2040, 3000 CA, Rotterdam, the Netherlands. devlaming@mdl.azr.nl

Accepted for publication 12 February 2001

Keywords: primary biliary cirrhosis; jaundice; ductopenia; portal tract; cholestasis; liver biopsy

Primary biliary cirrhosis (PBC) is a vanishing bile duct disorder ${ }^{1}$ of a highly variable, albeit slowly progressive, nature. Immunologically mediated destruction of interlobular and septal bile ducts, resulting in bile duct loss or ductopenia, is considered to be one of the main pathophysiological events leading ultimately to liver fibrosis and biliary cirrhosis. ${ }^{23}$ The histological appearance has been divided into four

\begin{abstract}
Department of Gastroenterology and Hepatology, University Hospital Rotterdam, the Netherlands F P Vleggaar $\mathrm{H} R$ van Buuren

Department of Pathology, University Hospital Rotterdam, the Netherlands P E Zondervan

Department of Pathology, Academic Medical Centre, Amsterdam, the Netherlands

F J W ten Kate

Department of Epidemiology and Biostatistics, Erasmus University Rotterdam, the Netherlands W C J Hop

Abstract

The clinical and pathological findings of four females with primary biliary cirrhosis (PBC) with an unusual and hitherto not well recognised course are reported. Patients suffered severe pruritus and weight loss with progressive icteric cholestasis which did not respond to such treatments as ursodeoxycholic acid and immunosuppressives. In all cases liver histology revealed marked bile duct loss without however significant fibrosis or cirrhosis. Further diagnostic studies and repeat biopsies confirmed the absence of liver cirrhosis as well as other potential causes of hyperbilirubinaemia. Comparison of the fibrosis-ductopenia relationship for our cases with that for a group of 101 noncirrhotic PBC patients indicated that in the former the severity of bile duct loss relative to the amount of fibrosis was significantly higher. The proportion of portal triads containing an interlobular bile duct was $3 \%, 4 \%, 6 \%$, and $10 \%$ compared with $45 \%$ (median; range $8.3-$ $100 \%)$ for controls $(\mathrm{p}<0.001)$. Three patients received a liver transplant $6-7$ years after the first manifestation of PBC because of progressive cholestasis, refractory pruritus, and weight loss, while the fourth patient is considering this option. In one case cirrhosis had developed at the time of transplantation while the others still had non-cirrhotic disease. These cases suggest that cholestatic jaundice in non-cirrhotic PBC may be secondary to extensive "premature" or accelerated intrahepatic bile duct loss. Although the extent of fibrosis may be limited initially, progression to cirrhosis appears to be inevitable in the long run. Despite intact protein synthesis and absence of cirrhotic complications, liver transplantation in the pre-cirrhotic stage for preventing malnutrition and to improve quality of life should be considered for these patients.

(Gut 2001;49:276-281)
\end{abstract}

stages, the last (stage IV) representing true cirrhosis. ${ }^{4}$ In general, jaundice is only encountered in the cirrhotic stage, ${ }^{5}$ probably as a consequence of both hepatocellular insufficiency and bile duct loss.

Jaundice in non-cirrhotic PBC is rare. In contrast with what is observed in the idiopathic adulthood ductopenia syndrome for example, ${ }^{6}$ it appears that the degree of intrahepatic bile duct loss is usually not severe enough to cause jaundice. Various-mainly extrahepaticfactors not specifically related to PBC, including hyperthyroidism, ${ }^{7}$ malignant lymphoma, ${ }^{89}$ liver metastases, certain drugs, ${ }^{10}$ haemolysis, ${ }^{11} 12$ concomitant autoimmune hepatitis flares, ${ }^{13}$ and major bile duct obstruction can cause jaundice in non-cirrhotic PBC.

We report here on a subgroup of PBC patients suffering from severe cholestatic icteric disease for whom no causative extrahepatic or intrahepatic factors other than profound ductopenia could be identified. Remarkably, this was not associated with histological evidence of cirrhosis or substantial fibrosis. A histomorphological study of these cases and a large group of non-cirrhotic PBC patients was performed to define the ductopenia-fibrosis relationship and to test the hypothesis that our cases exhibited extreme paucity of bile ducts in relation to the amount of fibrosis.

\section{Cases}

PATIENT NO 1

In 1994, a 39 year old Chinese woman presented with fatigue, pruritus, and jaundice. Her previous medical history was unremarkable. There was no history of alcohol or drug abuse, or familial liver problems. Laboratory investigations showed cholestatic serum liver values (table 1), elevated IgM levels, and an antimitochondrial antibody (AMA) titre of 1:10240. Total serum bilirubin was $78 \mu \mathrm{mol} / 1$ (normal <18) while albumin, clotting factors, and platelet count were normal. Other aetiological studies for viral hepatitis, haemochromatosis, $\alpha_{1}$ antitrypsin deficiency, and Wilson's disease were negative. A liver biopsy revealed severe ductopenia (table 2) and non-cirrhotic (stage II) PBC. Abdominal ultrasound was normal: smooth liver surface, no collaterals or ascites, and normal spleen size and portal venous flow pattern. Subsequent treatment with ursodeoxycholic acid (UDCA) and later with prednisone and azathioprine did not result in improvements in symptoms, serum bilirubin

Abbreviations used in this paper: $\mathrm{PBC}$, primary biliary cirrhosis; AMA, antimitochondrial antibody; UDCA, ursodeoxycholic acid. 
Table 1 Clinical characteristics and diagnostic findings

\begin{tabular}{|c|c|c|c|c|}
\hline \multirow[b]{3}{*}{ Age (y) } & \multicolumn{4}{|l|}{ Patient No } \\
\hline & 1 & 2 & 3 & 4 \\
\hline & 39 & 43 & 43 & 47 \\
\hline Sex & $\mathrm{F}$ & $\mathrm{F}$ & $\mathrm{F}$ & $\mathrm{F}$ \\
\hline Ethnic background & Chinese & Caucasian & Caucasian & Caucasian \\
\hline \multicolumn{5}{|l|}{ Laboratory values } \\
\hline AMA & Positive $1: 10240$ & Positive $1: 10240$ & Positive $1: 1280$ & Negative \\
\hline M-2 antibody & Positive & Positive & Positive & Negative \\
\hline ANA & Positive $1: 40$ & Positive $1: 80$ & Negative & Positive 1:640 \\
\hline Total bilirubin $(\mu \mathrm{mol} / 1$; normal $<18)$ & 78 & 77 & 168 & 129 \\
\hline $\mathrm{APh}(\mathrm{U} / 1 ;$ normal $<75)$ & 709 & 926 & 761 & 848 \\
\hline ALT (U/1; normal <50) & 336 & 287 & 56 & 194 \\
\hline $\operatorname{IgG}(\mathrm{g} / 1 ;$ normal $<15.5)$ & 22.9 & 14.3 & 10.6 & 13.6 \\
\hline $\operatorname{IgM}(\mathrm{g} / \mathrm{l} ;$ normal $<2.8)$ & 4.07 & 4.13 & 4.52 & 9.19 \\
\hline Bile salts $(\mu \mathrm{mol} / 1 ;$ normal $<10)$ & 840 & 240 & 400 & 720 \\
\hline Cholesterol $(\mathrm{mmol} / 1$; normal $<6.5)$ & 11.3 & 8.6 & 32.6 & 16.0 \\
\hline $\mathrm{TSH}(\mathrm{mU} / 1 ;$ normal $=0.20-4.20)$ & 0.54 & 0.68 & 1.23 & 0.97 \\
\hline $\mathrm{LD}(\mathrm{U} / 1$; normal <480) & 308 & 345 & 221 & 364 \\
\hline \multicolumn{5}{|l|}{ Radiology } \\
\hline Endoscopic cholangiography & na & No stenoses & No stenoses & No stenoses \\
\hline Abdominal ultrasonography & Normal & Normal & Normal & Normal \\
\hline Spleen size at US $(\mathrm{cm})$ & Not enlarged & $9-10$ & 12 & 15 \\
\hline Visual liver assessment & na & Normal & Normal & Normal \\
\hline Revised AIH score & +8 & +8 & +2 & +8 \\
\hline Upper GI endoscopy & na & No ph & No ph & No ph \\
\hline
\end{tabular}

Data obtained at the time of liver biopsy, as indicated in the text.

na, not available; GI, gastrointestinal; ph, portal hypertension; AMA, antimitochondrial antibodies; M-2 antibody, (ELISA test) antibody directed against the E2 subunit of mitochondrial pyruvate dehydrogenase; ANA, antinuclear antibodies; APh, alkaline phosphatase; ALT, alanine aminotransferase; IgG, immunoglobulin G; IgM, immunoglobulin M; TSH, thyroid stimulating hormone; LD, lactate dehydrogenase.

Table 2 Histological findings

\begin{tabular}{lllll}
\hline & \multicolumn{3}{l}{ Patient No } \\
\cline { 2 - 5 } & $\mathrm{I}$ & $\mathrm{II}$ & $\mathrm{III}$ & $\mathrm{IV}$ \\
\hline Biopsy length (mm) & 21 & 28 & 18 & 25 \\
Portal tracts (n) & 28 & 18 & 10 & 30 \\
Portal tract with interlobular bile duct & 1 & 1 & 1 & 1 \\
$\quad(\mathrm{n})$ & & & & \\
Inflammatory bile duct lesion (Y/N) & $\mathrm{Y}$ & $\mathrm{N}$ & $\mathrm{Y}$ & $\mathrm{N}$ \\
Bile duct proliferation (0-3) & 2 & 1 & 1 & 3 \\
Granulomas (Y/N) & $\mathrm{Y}$ & $\mathrm{N}$ & $\mathrm{N}$ & $\mathrm{N}$ \\
Cholestasis (0-3) & 0 & 0 & 1 & 1 \\
Cu accumulation (0-3) & 1 & 2 & 2 & 2 \\
Portal infiltrate (0-4) & 2 & 1 & 1 & 2 \\
Piecemeal necrosis (0-4) & 2 & 1 & 0 & 1 \\
Fibrosis (0-4) & 2 & 1 & 1 & 3 \\
\hline
\end{tabular}

level, or other laboratory parameters. Four years later a second biopsy was taken. At that time serum bilirubin level was $103 \mu \mathrm{mol} / \mathrm{l}$. Serum albumin and clotting factors were normal but platelets were slightly decreased $\left(122 \times 10^{9} / 1\right.$, normal $\left.130-340 \times 10^{9} / 1\right)$. Abdominal ultrasound was normal but slight splenomegaly was noted. Histological examination showed two bile ducts in a total of 26 portal tracts. The degree of fibrosis had increased significantly and the beginning of nodularity of the liver parenchyma was noted (PBC stage III). At present, she is considering the possibility of liver transplantation.

PATIENT NO 2

In 1992, a previously healthy 38 year old Caucasian woman presented with pruritus and fatigue. A diagnosis of PBC was made on the basis of a positive test for AMA (titre 1:10240), the cholestatic serum liver profile (total bilirubin $34 \mu \mathrm{mol} / \mathrm{l}$ ), elevated IgM levels, and characteristic histology. Studies for viral and metabolic liver diseases were negative. UDCA therapy was instituted but did not result in any improvement in serum liver tests. Treatment with antipruritics such as cholestyramine, rifampicin, naltrexone, and oxazepam was unsuccessful. In 1997, combined prednisone and azathioprine treatment was given for three months without amelioration of complaints. One year later she was referred to the University Hospital Rotterdam. Jaundice (total bilirubin $77 \mu \mathrm{mol} / \mathrm{l}$ ) and marked cholestatic serum liver values were found. Histological examination of the liver showed non-cirrhotic stage I PBC. In one of 18 portal tracts one bile duct could be identified (table 2). Severe pruritus and progressive weight loss $(13 \mathrm{~kg}$ in three years) were the main indications for performing liver transplantation 18 months later. Histological examination of a biopsy specimen of the liver explant showed PBC stage I with five intact bile ducts in 32 portal tracts.

PATIENT NO 3

In 1990, a 38 year old Caucasian woman presented with pruritus and arthralgia. Her previous medical history was unremarkable. On the basis of cholestatic serum liver values, elevated serum IgM levels, positive AMA serology, and liver biopsy findings a diagnosis of PBC (stage I-II) was made. Other aetiological studies for viral and metabolic liver disorders were negative. During the following five years serum bilirubin gradually increased from $24 \mu \mathrm{mol} / 1$ in 1992 to 92 $\mu \mathrm{mol} / 1$ in 1993 and to $187 \mu \mathrm{mol} / 1$ in 1995 . During these years serum albumin, platelets, and clotting factors were normal. Further liver biopsies were taken in 1992 (table 2), 1993, and 1995, all showing ductopenia of increasing severity but only slight fibrosis. During cholecystectomy in 1993 the liver appeared normal. Treatment with UDCA and prednisone did not result in evident symptomatic or biochemical improvements. Severe fatigue and pruritus persisted despite treatment with antipruritics such as cholestyramine, rifampicin, and naltrexone. Abdominal ultrasonography and upper gastrointestinal endoscopy showed no evidence 


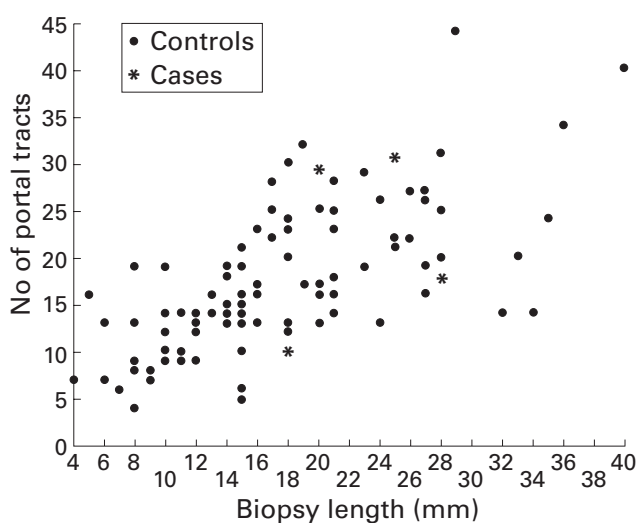

Figure 1 Scatterplot showing the relationship between biopsy length and number of portal tracts.

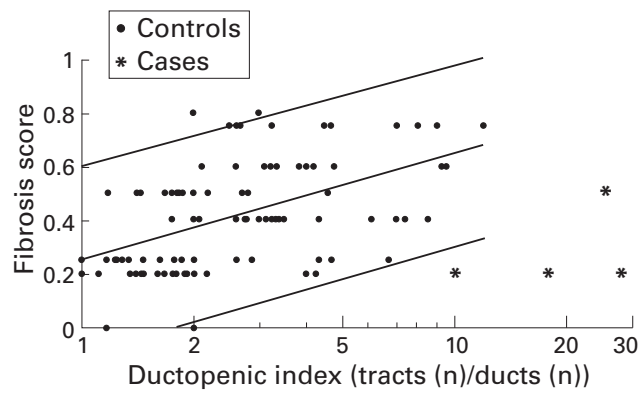

Figure 2 Scatterplot showing the relationship between the ductopenic index (ratio of portal tracts (n) to ducts (n)) and fibrosis score. A high index indicates severe ductopenia. The central line indicates the least squares regression line. The upper line represents the 97.5 percentile and the lower line the 2.5 percentile. Note the logarithmically scaled horizontal axis. Three of four cases fell outside the 95\% reference interval of the control biopsy specimens.

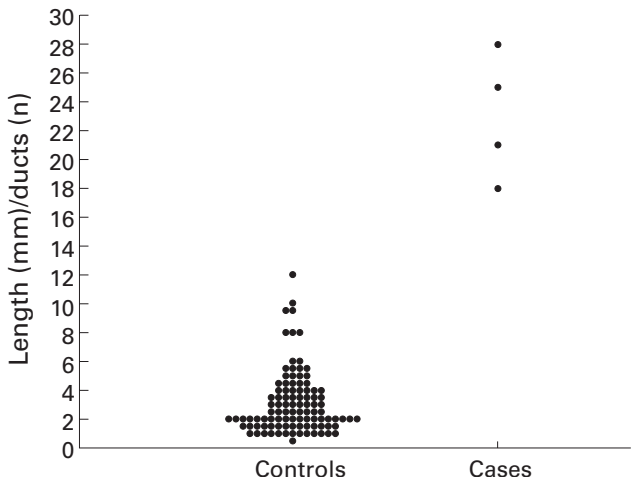

Figure 3 Plot showing the difference in length $(\mathrm{mm}) /$ ducts (n) ratio between the controls and cases. A high ratio indicates severe ductopenia.

of cirrhosis or portal hypertension. She was referred for transplantation in 1995. The weight loss was $7 \mathrm{~kg}$ when she received a transplant in 1997. The explant showed biliary cirrhosis (PBC stage IV).

\section{PATIENT NO 4}

In 1993, this 47 year old Caucasian was diagnosed with AMA negative PBC after she presented with weight loss and pruritus. The diagnosis was based on serum liver tests indicating cholestasis, elevated serum IgM levels, and a liver biopsy showing chronic non-suppurative destructive cholangitis with portal granulomas. Other aetiological studies for viral hepatitis, haemochromatosis, $\alpha_{1}$ antitrypsin deficiency, and Wilson's disease were negative. Pruritus worsened after institution of treatment with UDCA and failed to respond to cholestyramine, rifampicin, and naltrexone. Combination treatment with prednisone and azathioprine was given for one year without any symptomatic or biochemical improvement. In February 1998, shortly after prednisone was discontinued, severe jaundice (total bilirubin $232 \mu \mathrm{mol} / \mathrm{l}$ ) with aggravating pruritus developed. Serum cholesterol increased from $8-9 \mathrm{mmol} / \mathrm{l}$ to levels as high as $46 \mathrm{mmol} / \mathrm{l}$ while high density lipoprotein cholesterol decreased to subnormal levels. Periocular and palmar xanthomatous skin abnormalities occurred and her body weight decreased from 85 to $55 \mathrm{~kg}$ within a period of one year. In 1999 liver transplantation was performed. The liver explant showed non-cirrhotic stage II-III PBC with extreme bile duct paucity (table 2).

\section{Patients and methods}

The clinical, biochemical, and histological findings of our cases suggested that in these patients the course of the disease deviated from "normal". Most strikingly, the extent of bile duct loss seemed to be excessive in relation to the amount of fibrosis. To substantiate this impression, the quantified histological findings in our patients were compared with those of a group of 101 consecutive untreated PBC patients with noncirrhotic histology. This population was collected between 1990 and 1998 during a prospective cohort study of PBC in the Netherlands. ${ }^{14}$ Total serum bilirubin levels in this group were lower than $23 \mu \mathrm{mol} / 1$ at the time of liver biopsy. In both our cases and the reference population, liver specimens were obtained percutaneously using Tru-cut or Menghini 14-16 gauge needles. Biopsies were fixed in formalin and processed routinely into paraffin blocks. Sections were stained with haematoxylin and eosin as well as anticytokeratin 19 antibodies.

The following features of each specimen were assessed: aggregate length $(\mathrm{mm})$, number of portal tracts, number of portal tracts with an interlobular bile duct, degree of fibrosis, and Ludwig stage. ${ }^{4}$ The severity of fibrosis was expressed as a value ranging from 0 to $4^{15}$ and from 0 to 5 for biopsies scored between 1990 and March 1994 and between March 1994 and 1998, respectively. The maximum score represents cirrhosis. The amount of fibrosis was expressed as a fibrosis score, defined as a proportion of the maximum score. One biopsy per patient was included in the statistical analysis.

The proportion of bile ducts was calculated by dividing the total number of portal tracts with an interlobular bile duct by the total number of portal tracts in each biopsy specimen. A ductopenic index was calculated by dividing the total number of portal tracts by the total number of portal tracts containing an interlobular bile duct. Thus the higher the ductopenic index the more serious the loss of bile ducts. The degree of bile duct loss was also expressed as biopsy length ( $\mathrm{mm}$ ) divided by the number of bile ducts. 
For the index cases, the possibility of significant bile duct obstruction, which could possibly account for the discrepancy between the clinical features and the non-cirrhotic histology, was assessed by means of endoscopic retrograde cholangiography and/or ultrasonography. Hyperthyroidism was evaluated by measurement of serum concentrations of thyroid stimulating hormone. To exclude concomitant autoimmune hepatitis, the revised international score ${ }^{16}$ was calculated. Haemolysis was assessed by serum lactate dehydrogenase and haematological indices. Abdominal ultrasound with measurement of spleen size, upper gastrointestinal endoscopy for detection of oesophagogastric varices, and visual inspection of the liver during laparoscopy or laparotomy were performed to further exclude the presence of cirrhosis. Statistical analysis was performed with Stata 4.0 for Windows. Correlations were calculated using Pearson's $(r)$ or Spearman's $\left(r_{\mathrm{s}}\right)$ tests. A p level $<0.05$ was considered statistically significant.

\section{Results}

Clinical, biochemical, histological, and radiological characteristics of the four index patients are shown in tables 1 and 2 . All were females with a median age of 43 years. The mean age of the reference group $(\mathrm{n}=101)$ was 56 years (range $37-73$ ); 87\% were female and 95\% were AMA positive. Ludwig stages I, II, and III were found in $20(20 \%), 51(50 \%)$, and $30(30 \%)$ biopsies, respectively.

Median length of the 101 control biopsy specimens was $16 \mathrm{~mm}$ (range 4-40) and the median number of portal tracts per biopsy was 16 (range 4-44). The median number of portal tracts $/ \mathrm{mm}$ of liver tissue was $1.0 \quad(95 \%$ confidence interval 0.98-1.15). The number of portal tracts correlated well with the aggregate length of the biopsy core $\left(r_{\mathrm{s}} 0.7, \mathrm{p}<0.001\right)$. The four cases did not deviate from the pattern among controls (fig 1).

For our four cases, the proportion of portal tracts containing normal bile ducts was $3 \%$, $4 \%, 6 \%$, and $10 \%$, yielding ductopenic indices of $30,28,18$, and 10 , respectively. For the reference group, the median proportion of portal tracts with a bile duct was $45 \%$ (range $8.3-100 \%)$, significantly different from the cases (Mann-Whitney test, $\mathrm{p}<0.001$ ). The median ductopenic index for the reference group was 2.2 (range 1-12).

The relationship between the degree of ductopenia and fibrosis is shown in fig 2 . For the reference group, the ductopenic index was positively correlated with the degree of fibrosis $(r=0.51$ after logarithmic transformation of the ductopenic index to obtain normal distribution; $\mathrm{p}<0.001$ ). This implies that only $26 \%$ (that is, $r^{2}$ ) of the variability in fibrosis may be attributed to an association with the severity of ductopenia. Three of four cases fell outside the 95\% reference interval (fig 2). Therefore, the degree of bile duct loss was significantly higher in our patients, especially when the small amount of fibrosis was taken into account (fibrosis score 0.2 in three cases and 0.5 in one). When the number of bile ducts was related to biopsy length, instead of the number of portal tracts, this ratio was significantly $(p<0.001)$ higher for our cases compared with controls (fig 3). The extreme ductopenia is illustrated by a keratin 19 stained biopsy slide for one of the cases, showing nearly total absence of pre-existent bile ducts (fig 4).

Other causes that might explain the apparent discrepancy between the severity of cholestasis and hyperbilirubinaemia versus the minimal fibrosis in these PBC patients could not be identified. In particular, no evidence of hyperthyroidism, haemolysis, autoimmune hepatitis (table 1), previous use of agents known to induce cholestasis, or major bile duct obstruction was found. Macroscopic examination of the liver, performed in three cases, showed normal livers without evidence of cirrhosis. In addition, ultrasonography $(n=4)$ and upper gastrointestinal endoscopy $(n=3)$ did not reveal signs of portal hypertension or evidence of other conditions, including cholelithiasis, liver metastases, or lymphoma. Serum values for albumin and antithrombin III were within the normal range in all cases, reflecting intact protein synthesis.

For the three patients who underwent liver transplantation, the predicted one and two year survival rates, according to the original Mayo risk score model (http://www.mayo.edu/int$\mathrm{med} / \mathrm{gi} / \mathrm{model} /$ mayomodl-1.htm) at the time of referral varied from $94 \%$ to $97 \%$ and from $84 \%$ to $94 \%$, respectively.

\section{Discussion}

The cases described in the present report indicate that among patients with PBC a subgroup can be identified, characterised clinically by severe cholestasis and histologically by extreme ductopenia which is not accompanied by significant liver fibrosis or cirrhosis. The effect of medical treatment, including a variety of antipruretics, UDCA, and immunosuppressives was disappointing. Also, considering the markedly decreased quality of life of affected individuals and the adverse effect of chronic severe cholestasis on nutritional status, this progressive disease evolves in the course of a few years to the stage where liver transplantation should be considered. Based on our experience we believe that the absence of cirrhosis should not unnecessarily delay transplantation. The findings for this subgroup are at variance with the usual course of the disease whereby severe cholestasis and jaundice are only encountered in patients with cirrhotic histology.

Histological evaluation of the liver using needle biopsy may be hampered by the possibility of sampling error. The accuracy of diagnosing cirrhosis, and consequently its absence, by percutaneous needle biopsy alone has been reported to be poor. ${ }^{17}$ However, a combination of this procedure with ultrasonography enhances sensitivity to nearly $100 \% .^{17}{ }^{18}$ Histology was combined with ultrasonography in our four cases. In addition, in three cases macroscopic assessment of the liver as well as upper gastrointestinal endoscopy was performed to further minimise the chances of missing a diagnosis of cirrhosis. 
Variability in the total size of the biopsy core influences the yield of portal tracts. The scatterplot (fig 1) indicates that the biopsies obtained from our patients were comparable with those from controls. The data showed that approximately one portal tract $/ \mathrm{mm}$ of needle biopsy tissue was found, confirming the previously published $1: 1$ ratio (portal tract: $\mathrm{mm}$ needle biopsy) for the normal adult human liver. ${ }^{19}$ Sampling error may also weaken the data on the severity of ductopenia. In this study little overlap in degree of ductopenia between the reference group and our cases was found. However, the difference in degree of bile duct loss between the case and control groups was statistically significant, both when the number of bile ducts was related to the number of portal tracts as well as to the length of the biopsy specimen. Furthermore, a repeat biopsy in two of the cases (one non-cirrhotic liver explant) confirmed the presence of striking ductopenia.

The study allows only speculations on the aetiopathophysiological differences between patients with the non-cirrhotic severe ductopenia variant and those with the more conventional course. We found that the relationship between ductopenia and fibrosis, although present, was not very convincing. We hypothesise that in exceptional cases a particularly aggressive form of immune mediated bile duct destruction results in extensive ductopenia within a comparatively short period of time. The relatively young age of our patients at presentation with severe cholestasis points to this possibility. Initially, fibrogenesis seems to lag behind the rate of bile duct destruction. Nevertheless, as indicated by the histological

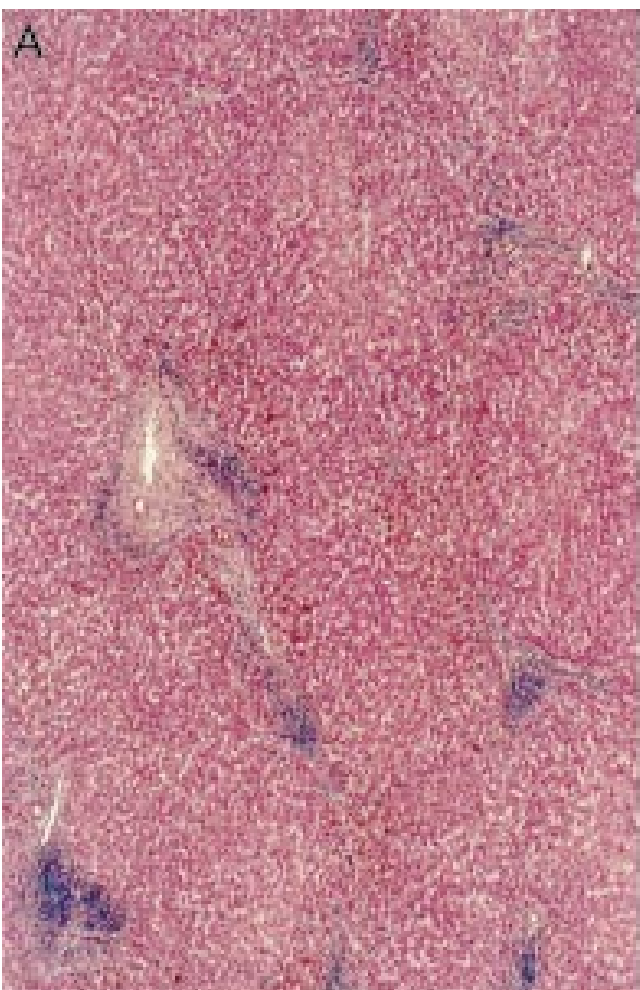

evolution in our patients, progressive fibrosis eventually does develop.

The mechanism of the frequently observed hypercholesterolaemia in PBC is incompletely understood. In two of our patients cholesterol levels were found to be exceptionally high. A biliary secretion defect due to ductopenia sec may not satisfactorily explain this finding as the severe ductopenia of end stage cirrhotic disease is not associated with cholesterol levels of the observed magnitude. In the three patients who were transplanted cholesterol levels normalised rapidly.

In three of the four reported patients, liver histological and laboratory examination showed periportal piecemeal necrosis of slight to moderate severity and the presence of antinuclear antibodies in association with high serum transaminase levels. These findings may suggest an overlap syndrome, in particular with autoimmune hepatitis. On the other hand, serum immunoglobulin $G$ levels were normal or only slightly elevated and application of the international autoimmune hepatitis score yielded scores indicating a very low probability of autoimmune hepatitis. Finally, immunosuppressive treatment had no beneficial effect. We believe that, although some findings are somewhat unusual with respect to "classical" PBC, there is insufficient evidence for a PBCautoimmune hepatitis overlap syndrome in our patients.

Previously, Nakanuma et al suggested extensive bile duct loss as a potential cause of cholestatic jaundice in non-cirrhotic $\mathrm{PBC}^{20}$ without however reporting quantitative histological data. Our study suggests that the proportion of portal

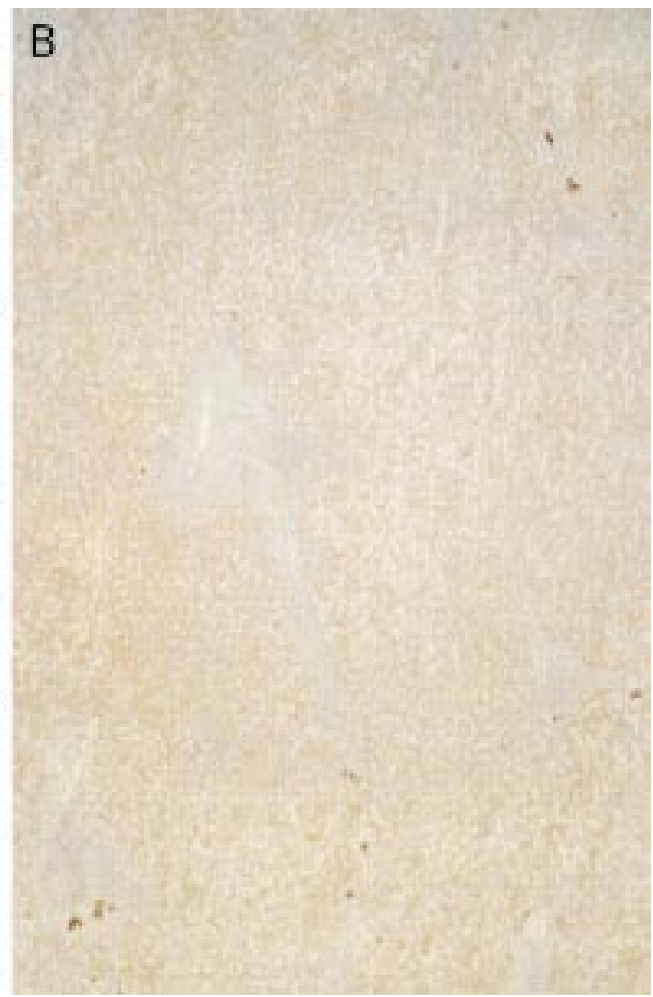

Figure 4 (A) Haematoxylin-eosin coloured liver biopsy from patient No 2 showing at least four portal tracts. The amount of fibrosis is very limited and there are no portoportal or portoseptal connections. (B) Anticytokeratin 19 (keratin 19) stained liver biopsy from patient No 2 showing the same portal tracts as in (A) with total absence of pre-existent interlobular bile ducts and only very moderate ductular proliferation (darkish brown coloured cells). 
tracts with an intact interlobular bile duct has to be less than $10 \%$ in order to produce substantial hyperbilirubinaemia. Mild ductopenia, defined as a proportion of portal tracts with an intact interlobular bile duct $>50 \%$, was not shown to be associated with a rise in serum bilirubin concentration in adults with "idiopathic biliary ductopenia". ${ }^{21}$ Patent bile ducts in $10-50 \%$ of portal tracts, as was found in the large majority of patients in the reference group, was also not associated with hyperbilirubinaemia. These percentages should not be regarded as absolute limits but rather as broad indications. Also, when assessing the degree of ductopenia, the size of the biopsy specimen should always be taken into account. For a reliable assessment of ductopenia a minimum of 20 evaluable portal tracts has been suggested. ${ }^{22}$ In clinical practice however this is not always feasible.

In 1978, Popper hypothesised that in PBC two pathways may lead to cirrhosis ${ }^{2}$ : one is the consequence of biliary destruction within the portal triads and the other is due to periportal interface hepatitis that is uniformly found in PBC, albeit to a variable extent. These two mechanisms may be operative in different degrees in individual patients. Consequently, one could speculate that PBC may have a wide range of phenotypical expressions, varying from a PBC-autoimmune overlap syndrome on the one hand to the "premature ductopenic variant" on the other. Although it appears that both manifestations eventually may lead to cirrhosis, the name of the disease clearly needs to be revised. "Primary intrahepatic cholangitis" may be a more appropriate term.

In conclusion, cholestatic jaundice in noncirrhotic PBC may be secondary to an unusually accelerated intrahepatic bile duct loss. Although the extent of fibrosis in affected patients may be limited initially, progression to cirrhosis seems to be inevitable. Despite intact protein synthesis and the absence of cirrhotic complications, liver transplantation in the precirrhotic stage for treatment of pruritus and (prevention of) progressive weight loss due to malabsorption should be considered. In the process of decision making the Mayo risk model does not seem to be a helpful instrument in this particular subgroup of PBC patients.

We would like to thank Professor V Desmet for studying some of the biopsy specimens and for critically reviewing the manuscript.

\section{Appendix}

THE DUTCH MULTICENTER PBC STUDY GROUP R Adang, V Verstappen, St Maartens Gasthuis Venlo; P Batenburg, Zuiderziekenhuis Rotterdam; $\mathrm{G}$ van Berge Henegouwen, J van Hattum, University Hospital Utrecht; P Biemond, L Lie, Ziekenhuis St Franciscus Roosendaal; J Breed, St fans Gasthuis Weert; C van Deursen, Ziekenhuis De Wever en Gregorius Brunssum; Th van Ditzhuijsen, I van Munster, Bosch Medicentrum Den Bosch; O van Dobbenburgh, Het Nieuwe Spittaal Zutphen; L Engels, Maasland Ziekenhuis, Sittard; J Ferwerda, Kennemer Gasthuis Haarlem; J Groen, Ziekenhuis St Fansdal, Harderwijk; K Heering, Groene Hart Ziekenhuis Gouda; P van Hees, St Antonius Ziekenhuis, Nieuwegein; E vd Hoek, J de Bruijne, Carolus Ziekenhuis Den Bosch; M Houben, $\mathrm{R}$ Valentijn, Rode Kruis Ziekenhuis Den Haag; J Kapelle, P Spoelstra, Medisch Centrum Leeuwarden; M KerbertDreteler, J van Lijf, Medisch Spectrum Twente Enschede; I
Klompmaker, E Haagsma, University Hospital Groningen; G Koek, W Hameeteman, University Hospital Maastricht; J Lambert, Sophia Ziekenhuis Zwolle; P Leeuwerik, Ziekenhuis Lievensberg Bergen op Zoom; B Looij, Maasland Ziekenhuis Geleen; A Luckers, Maasziekenhuis Boxmeer; A van Milligen de Wit, Elisabeth Ziekenhuis Tilburg; C van Nieuwkerk, University Hospital Free University Amsterdam; J den OudenMuller, A van Tilburg, St Franciscus Gasthuis Rotterdam; S Peters, P Tjepkema, Ifsselmeerziekenhuizen Lelystad; G Ras, Ignatius Ziekenhuis Breda; M Rijk, Ziekenhuis De Baronie Breda; R Robijn, Ziekenhuiscentrum Apeldoorn; S Schalm, University Hospital Rotterdam; J Scherpenisse, Reinier de Graaf Gasthuis Delft; A Stronkhorst, Catharina Ziekenhuis Eindhoven; T Tan, Streekziekenhuis MiddenTwente Hengelo; J Thijs, Ziekenhuis Bethesda Hoogeveen; K te Velde, Deventer Ziekenhuizen Deventer; M VidakovicVukic, Lucas Andreas Ziekenhuis Amsterdam; A van Vliet, R Beukers, H Ponssen, Albert Schweitzer Ziekenhuis Dordrecht; $\mathrm{R}$ de Vries, C Mulder, J Thies, Ziekenhuis Rijnstate Arnhem; S vd Werf, Westeinde Ziekenhuis Den Haag; B Witteman, J van Bergeijk, Ziekenhuis De Gelderse Vallei Wageningen; R van Zanten, Twenteborg Ziekenhuis Almelo; R Zeijen, Schieland Ziekenhuis Schiedam; R Zwertbroek, Westfries Gasthuis Hoorn; A Saleh, Elisabeth Hospitaal Willemstad, Curacao.

1 Desmet VJ. Vanishing bile duct disorders. In: Boyer JL, Ockner RK, eds. Progress in liver disease. Philadelphia: WB Saunders, 1992:89-121

2 Popper H. The problem of histologic evaluation of primary 1978;379:99-102.

3 Neuberger J. Primary biliary cirrhosis. Lancet 1997;350: $875-9$.

4 Ludwig J, Dickson ER, McDonald GS. Staging of chronic nonsuppurative destructive cholangitis (syndrome of primary biliary cirrhosis). Virchows Arch A Pathol Anat Histol mary biliary cirrhosis

5 Kaplan MM. Primary biliary cirrhosis. N Engl f Med 1996; 335:1570-80.

6 Ludwig J, Rosen CB, Lindor KD, et al. Chronic cholestasis in a young man. Hepatology 1994;20:1351-5.

7 Thompson NP, Leader S, Jamieson CP, et al. Reversible jaundice in primary biliary cirrhosis due to hyperthyroidism. Gastroenterology 1994;106:1342-3.

8 Hubscher SG, Lumley MA, Elias E. Vanishing bile duct syndrome: a possible mechanism for intrahepatic cholestasis in Hodgkin's lymphoma. Hepatology 1993;17:70-7.

9 Crosbie OM, Crown JP, Nolan NP, et al. Resolution of paraneoplastic bile duct paucity following successful treatment of Hodgkin's disease. Hepatology 1997;26:5-8.

10 Desmet VJ. Vanishing bile duct syndrome in drug-induced liver disease. 7 Hepatol 1997;1:31-5.

11 Chen CY, Lu CL, Chiu CF, et al. Primary biliary cirrhosis associated with mixed type autoimmune hemolytic anemia and sicca syndrome: a case report and review of literature. Am $\mathcal{F}$ Gastroenterol 1997;92:1547-9.

12 Mahl MA, von Schonfeld J, Uppenkamp M, et al. Hemolytic anemia as cause of a marked bilirubin increase in primary biliary cirrhosis. Dtsch Med Wochenschr 1996;121:1226-8.

13 Chazouilleres O, Wendum D, Serfaty L, et al. Primary biliary cirrhosis-autoimmune hepatitis overlap syndrome: clinical features and response to therapy. Hepatology 1998; 28:296-301.

14 van Hoogstraten $\mathrm{HJF}$, Hansen BE, van Burren $\mathrm{HR}$, et al. Prognostic factors and long-term effects of ursodeoxycholic acid on liver biochemical parameters in patients with primary biliary cirrhosis. I Hepatol 1999;31:256-62.

15 Desmet VJ, Gerber M, Hoofnagle JH, et al. Classification of chronic hepatitis: diagnosis, grading and staging. Hepatology 1994;19:1513-20.

16 Alvarez F, Berg PA, Bianchi FB, et al. International autoimmune hepatitis group report: review of criteria for diagnosis of autoimmune hepatitis. F Hepatol 1999;31:929-38.

17 Gaiano S, Gramantierie L, Venturoli N, et al. What is the criterion for differentiating chronic hepatitis from compensated cirrhosis? A prospective study comparing ultrasonography and percutaneous liver biopsy. F Hepatol 1997;6:979-85.

18 Schalm SW. The diagnosis of cirrhosis: clinical relevance and methodology. 7 Hepatol 1997;27:1118-19.

19 Crawford AR, Lin XZ, Crawford JM. The normal adult human liver biopsy: a quantitative reference standard. Hepatology 1998;28:323-31.

20 Nakanuma Y, Hoso M, Mizuno Y, et al. Pathologic study of primary biliary cirrhosis of early histologic stages presenting cholestatic jaundice. Liver 1988;8:319-24.

21 Moreno A, Carreno V, Cano A, et al. Idiopathic biliary ductopenia in adults without symptoms of liver disease. $N$ Engl topenia in adults without
$\mathcal{7}$ Med $1997 ; 336: 835-8$.

22 Ludwig J. Idiopathic adulthood ductopenia: an update. Mayo Clin Proc 1998;73:285-91.

23 Schalm SW, van Buuren HR. Early cirrhosis - or primary cholangitis? Lancet 1997;349:285. 